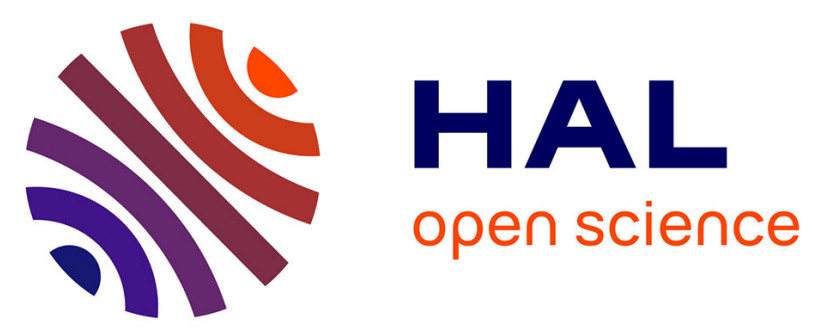

\title{
Voxel-based mapping of brain gray matter volume and glucose metabolism profiles in normal aging.
}

Grégoria Kalpouzos, Gaël Chételat, Jean-Claude Baron, Brigitte Landeau, Katell Mevel, Christine Godeau, Louisa Barré, Jean-Marc Constans, Fausto Viader, Francis Eustache, et al.

\section{To cite this version:}

Grégoria Kalpouzos, Gaël Chételat, Jean-Claude Baron, Brigitte Landeau, Katell Mevel, et al.. Voxelbased mapping of brain gray matter volume and glucose metabolism profiles in normal aging.. Neurobiol Aging, 2009, 30 (1), pp.112-24. 10.1016/j.neurobiolaging.2007.05.019 . inserm-00277881

\section{HAL Id: inserm-00277881 https://www.hal.inserm.fr/inserm-00277881}

Submitted on 7 May 2008

HAL is a multi-disciplinary open access archive for the deposit and dissemination of scientific research documents, whether they are published or not. The documents may come from teaching and research institutions in France or abroad, or from public or private research centers.
L'archive ouverte pluridisciplinaire HAL, est destinée au dépôt et à la diffusion de documents scientifiques de niveau recherche, publiés ou non, émanant des établissements d'enseignement et de recherche français ou étrangers, des laboratoires publics ou privés. 
Voxel-based mapping of brain gray matter volume and glucose metabolism profiles in normal aging

Grégoria Kalpouzos $^{\mathrm{a}}$, Gaël Chételat ${ }^{\mathrm{a}}$, Jean-Claude Baron ${ }^{\mathrm{b}, \mathrm{c}}$, Brigitte Landeau ${ }^{\mathrm{a}}$, Katell Mevel ${ }^{\mathrm{a}}$, Christine Godeau ${ }^{\mathrm{b}}$, Louisa Barré ${ }^{\mathrm{d}}$, Jean-Marc Constans ${ }^{\mathrm{f}}$, Fausto Viader ${ }^{\mathrm{a}, \mathrm{e}}$, Francis Eustache ${ }^{\mathrm{a}}$, Béatrice Desgranges ${ }^{\mathrm{a}, *}$

${ }^{\text {a }}$ Inserm - EPHE - Université de Caen/Basse-Normandie, Unité de Recherche E0218, GIP Cyceron, Caen, France

${ }^{\mathrm{b}}$ Inserm, U 320, GIP Cyceron, Caen, France

${ }^{\mathrm{c}}$ University of Cambridge, Dept of Neurology, Cambridge, UK

${ }^{\mathrm{d}}$ UMR CEA 2 - FRE CNRS 2698, GIP Cyceron, Caen, France

${ }^{\mathrm{e}}$ CHU Côte de Nacre, Service de neurologie Vastel, Caen, France

${ }^{\mathrm{f}} \mathrm{CHU}$ Côte de Nacre, Unité de neuroradiologie, Caen, France

Running head: Structural and metabolic profiles of normal aging

*Corresponding author: B. Desgranges, Inserm - EPHE - Université de Caen/BasseNormandie, Unité de Recherche E0218, Laboratoire de Neuropsychologie, CHU Côte de Nacre, 14033 Caen Cedex, France. Tel: + 332310651 95, Fax : + 3323106 51 98, email: desgranges-b@chu-caen.fr 


\section{Abstract}

With age, the brain undergoes both structural and functional alterations, probably resulting in reported cognitive declines. Relatively few investigations have sought to identify those areas that remain intact with aging, or undergo the least deterioration, which might underlie cognitive preservations. Our aim here was to establish a comprehensive profile of both structural and functional changes in the aging brain, using up-to-date voxel-based methodology (i.e. optimized VBM procedure; resting-state ${ }^{18}$ FDG-PET with correction for partial volume effects) in 45 optimally healthy subjects aged 20-83 years. Negative and positive correlations between age and both gray matter volume and ${ }^{18}$ FDG uptake were assessed. The frontal cortex manifested the greatest deterioration, both structurally and functionally, whereas the anterior hippocampus, the thalamus and (functionally) the posterior cingulate cortex were the least affected. Our results support the developmental theory which postulates that the first regions to emerge phylogenetically and ontogenetically are the most resistant to age effects, and the last ones the most vulnerable. Furthermore, the lesser affected anterior hippocampal region, together with the lesser functional alteration of the posterior cingulate cortex, appear to mark the parting of the ways between normal aging and Alzheimer's disease, which is characterized by early and prominent deterioration of both structures.

Keywords: aging, structural magnetic resonance imaging, positron emission tomography, voxel-based morphometry, partial volume effects. 


\section{Introduction}

With age, the brain undergoes structural and functional deterioration, which is thought to be responsible for the reported cognitive decline $[3,62,47]$. Identifying the best-preserved areas, or rather the least altered, would perhaps provide insight into cognitive preservation with age $[30,56]$, including "cognitive reserve", i.e. the maintenance of cognitive performance even when specific brain areas can no longer support the relevant processes [9].

Overall, the literature consistently reports global brain atrophy in normal adults, generally more pronounced in frontal areas (for a review, [63]), often followed by parietal, temporal and insular gray matter (GM) loss $[1,2,29,31,70,81,87]$. As a result of different methodologies and inclusion criteria, other brain areas have been the matter of conflicting findings, notably the hippocampus. The "region of interest" procedure (ROI), which consists in selecting specific brain regions to address specific hypotheses, sometimes showed the hippocampus to undergo structural deterioration $[34,35,85]$, occasionally as strong as the prefrontal cortex $[66,67]$, but sometimes revealed no significant correlation between hippocampal volume and age, suggesting that this structure may be relatively preserved in normal aging $[8,17,40,80]$. Since this structure and adjacent areas are deteriorated first and foremost in Alzheimer's disease $[4,19,36]$, differentiating the mesial temporal GM evolution in normal and pathological aging constitutes a key issue. Recently, structural brain changes have been investigated using the 'optimized Voxel-Based Morphometry procedure' (VBM), which makes it possible to assess the whole brain without postulating prior hypotheses about specific regions of the brain. Authors have systematically reported GM loss in the frontal lobe with aging [1,29,31,37,38,81,84,87], also affecting the insula, Heschl gyrus, anterior cingulate cortex, sensorimotor areas and cerebellum. In spite of the objectivity of this method, studies led to somewhat contradictory results regarding the hippocampus: some authors have found this structure to be preserved with aging [29,31], whereas others have reported structural 
deterioration $[38,81,84,87]$. This discrepancy may result from the samples selected in these studies. Thus, preservation of the hippocampus was found when the sample covered a large life span (17-79 years in Good et al. [29] and 8-79 in Grieve et al. [31]), whereas atrophy was observed when age effects were evaluated within older samples, i.e. 50 or 60 years and over ([38,70,81, but see [84]). This suggests a non-linearity of hippocampal GM volume time course over time in normal aging, as recently supported by Allen et al. [2]. These authors, using ROI analyses (including frontal lobe, hippocampal and parahippocampal areas) by decades, found that the frontal cortex volume declined linearly and had the strongest age association, whereas the hippocampal volume remained steady until about 60 years of age, while thereafter its volume began to rapidly decline. Other methods have contributed to knowledge on age-related morphological changes, such as thickness of the cerebral cortex [75]. The authors showed prominent atrophy of the prefrontal cortex, and relative sparing of the temporal and parahippocampal cortices, corroborating several previous volumetric findings (see also [68]).

A few longitudinal studies have also been performed to address the issue of age-related GM volume time course. Most have revealed prominent GM loss in prefrontal regions $[40,59,65,71,76]$ with smaller but significant decline in other regions, notably in mesial temporal areas. Hippocampal GM losses have been found at a relatively advanced age $[40,65,76]$ or in subjects who had received a diagnosis of arterial hypertention [65]. The only longitudinal voxel-based analysis has generated similar results, i.e. a mesial temporal tissue loss, at a lesser degree however than the prefrontal cortex [69]. Overall, a hippocampal atrophy has been often reported in the available longitudinal studies, but it appears to occur late in life, and even then to be relatively modest. 
Resting-state SPECT and PET studies have consistently highlighted a metabolic deterioration of the frontal and anterior cingulate cortices $[12,28,32,42,44,48,49,54,58,86,87,89]$. Of them, however, few have addressed the issue of regional metabolic preservation with aging $[32,49,58,86]$. All these studies being considered together, the occipital and posterior cingulate cortices, cerebellum, thalamus, basal ganglia and limbic structures have been reported to be the least altered. However, many contradictory results preclude any firm conclusion, given that decreased metabolism has been found in the limbic areas [42], basal ganglia [32], or posterior cingulate cortex [89]. Some methodological limitations could explain these discrepancies. Regional cerebral blood flow (rCBF) has been used as a marker of synaptic activity $[12,42,44,48]$, but this is suboptimal, as perfusion can be affected by many physiological variables. In addition, the partial volume effect (PVE), where the measured radiotracer concentration in small structures is influenced by surrounding structures [61], is particularly marked when cortical atrophy is present, as in normal aging. PVE correction (PVEc) was performed very recently in two PET studies, providing the most reliable results in this field so far $[33,87]$. Only the latter study [87] sought to highlight both deterioration and preservation. The authors report that only the right precentral gyrus remained relatively intact across age in men, as opposed to the left superior temporal and postcentral areas in women; they did not report data for the group as a whole. Finally, to our knowledge, a single recent study has longitudinally assessed functional age-related changes in the resting-state: BeasonHeld et al. [5] observed decreasing $\mathrm{rCBF}$ over 9 years mainly affecting the frontal areas, superior and middle temporal gyri, inferior occipital regions, mid-cingulate gyrus and midlevel thalami. Increased relative $\mathrm{rCBF}$ was observed mainly in frontal white matter, middle temporal gyrus, left hippocampus, inferior parietal, middle occipital and cerebellum, inferior part of the right thalamus, and putamen. 
To our knowledge, no study has assessed both structural and functional deterioration and relative preservation in normal aging in the same sample and using up-to-date methodology, i.e. voxel-based analyses, the optimized-VBM procedure and PVEc.

\section{Methods}

\subsection{Study population}

Forty-five healthy subjects aged between 20 and 83 years (mean: $49.4 \pm 18$ years, 24 females and 21 males) were selected according to stringent prospective inclusion/exclusion criteria. All were right-handed, had a minimum educational background of 9 years of schooling (mean: $13.1 \pm 2.5$ years) and were living at home. A semi-structured questionnaire was used by senior clinical neurologists (FV, JCB) to screen subjects' health. They were enrolled in these studies based on lack of abnormality of clinical, MRI, and neuropsychological examinations, as follows: 1) normal somatic examination, 2) body weight in the normal range, 3) no known vascular risk factor and smoking <10 cigarettes per day, 4) no alcohol or coffee abuse, according to DSM4 criteria, 5) blood pressure within normal limits or corrected to, 6) no history or clinical evidence of sensorineural loss, dementia, or psychiatric disorder (a formal psychiatric interview was not performed), 7) no current use of medication (except birth control pills, oestrogen replacement therapy, anti-hypertensive drugs), and especially no use of centrally acting drugs (sleeping pills, antidepressant drugs) for at least 6 weeks, 8) normal standard T1-, T2- and/or FLAIR- weighted MRI, and notably no significant white matter T2FLAIR-weighted hyperintensities (less than 5 pinpoint hyperintensities, size $<4 \mathrm{~mm}$ [46]). The Mattis dementia rating scale [45] was used for subjects over 50 years to exclude those suspected of neurodegenerative pathology (mean: $141.25 \pm 2.8$ ). They also underwent cognitive tasks assessing episodic memory (using the ESR task [15,25]), semantic memory (categorical fluency, [13]) and working memory (verbal span). In no subject there was any evidence of significant cognitive decline beyond that expected for normal aging, and no 
subject complained about their memory. All subjects underwent the entire protocol within a maximum period of two months.

This protocol was approved by the regional ethics committee. Subjects gave written consent to the procedure prior to the investigation.

\subsection{MRI data acquisition and processing}

The T1-weighted volume MRI scan consisted of a set of 128 adjacent axial slices parallel to the antero-posterior commissure (AC-PC) line, with a slice thickness of $1.5 \mathrm{~mm}$ and a voxel size of $0.94 \times 0.94 \mathrm{~mm}$, using the spoiled gradient echo sequence (SPGR) (repetition time $(\mathrm{TR})=10.3 \mathrm{~ms} ;$ echo time $(\mathrm{TE})=2.1 \mathrm{~ms}$; field of view $(\mathrm{FOV})=24 \mathrm{x} 18 \mathrm{~cm} ;$ matrix $=256 \mathrm{x}$ 192). All the MRI data sets were acquired from the same scanner (1.5 T Signa Advantage echospeed; General Electric) and with the same parameters. Standard correction for field inhomogeneities was applied.

The MRI data were analyzed using the optimized automated VBM procedure fully described elsewhere [29]. Briefly, this procedure consisted in generating a customized template (based on the 45 subjects' scans), and the segmentation and normalization of the MRI images using the customized priors. The resulting optimized parameters were then applied to the original scans, which were segmented, modulated and smoothed with a 12-mm isotropic Gaussian kernel. The modulation step was used to incorporate volume changes during normalization into the analysis.

\subsection{PET data acquisition and processing}

Data were collected using the high-resolution ECAT Exact HR+ PET scanner with an isotropic resolution of $4.6 \times 4.2 \times 4.2 \mathrm{~mm}$ (axial FOV $=158 \mathrm{~mm}$ ). The subjects fasted for at least 4 hours prior to scanning. The head was positioned on a headrest according to the 
cantho-meatal line and gently restrained with straps. ${ }^{18}$ FDG uptake was measured in the resting condition, with eyes closed, in a quiet and dark environment. A catheter was inserted into a vein in the arm to inject the radiotracer. Following ${ }^{68} \mathrm{Ga}$ transmission scans, $3-5 \mathrm{mCi}$ of ${ }^{18}$ FDG were injected as a bolus at time 0 , and a 10-min PET data acquisition began 50 min post-injection. 63 planes were acquired with septa out (volume acquisition), using a voxel size of $2.2 \times 2.2 \times 2.43 \mathrm{~mm}(x, y, z)$. During the PET data acquisition, laser beams were projected onto ink marks drawn on the forehead in order to carry out continuous monitoring of head motion and correct it, if necessary.

PET data were first corrected for PVE. We used an optimized voxel-based technique, originally devised by Müller-Gärtner et al. [52], and modified slightly by Rousset et al. [72]. This so-called 'modified Müller-Gärtner' method is described in detail by Quarantelli et al. [61] and is fully implemented in "PVE-lab" software. It makes it possible to correct for both the loss of GM activity due to spill-out onto non-GM tissues, and increases in GM activity, due to the spill-in from adjacent white matter (WM). Unlike the classic Müller-Gärtner method, which extracts the WM tracer uptake value from a large WM region, the modified method performs a more accurate estimation of this WM value, based on the ROI method proposed by Rousset et al. [73]. The latter takes into account both the spill-in and spill-out effects on any possible pair of ROIs.

In order to obtain accurate PET data, the images were subjected to coregistration onto their corresponding MR images and to spatial normalization on the same customized template as that used for the MR images. We used the mutual information coregistration approach of SPM2 ("between modality coregistration using information theory"; see [18]). PET data sets were resliced ( $2 \times 2 \times 2 \mathrm{~mm})$ and smoothed with a 14-mm isotropic Gaussian filter to blur individual variations in gyral anatomy and to increase the signal-to-noise ratio. 
MRI and PET data were masked so that only GM voxels of interest were considered in further analyses. This mask was obtained by thresholding the customized GM template to an absolute value $>0.5$, corresponding to more than $50 \%$ chance to belong to GM. The same mask was then applied to both MRI and PET datasets. Using the "single-subject: covariates only" routine of SPM2, with age as a covariate, correlations were computed across the 45 subjects. First, using the classic "no global normalization" routine of SPM, we assessed negative correlations between age and absolute GM volume to obtain absolute age-related GM volume loss (results are presented in the section 3.1). Second, the MRI data were re-analyzed separately using the "proportional scaling" routine of SPM. Dividing the intensity value of each voxel by the mean intensity value of all the voxels allowed us to assess positive correlations between age and relative GM voxel by voxel and then to highlight the regions that underwent less GM loss than the global age-related GM loss (results are presented in the section 3.2). Third, the classic and necessary "proportional scaling" routine was also applied to PVEc PET data to control for individual variations in total ${ }^{18} \mathrm{FDG}$ uptake. To assess regional changes, both negative and positive voxel by voxel correlations were performed between neuroimaging data and age. All these analyses were performed using a statistical threshold of $\mathrm{p}<.01$ FDR, corrected for multiple comparisons, with a minimum cluster size $\mathrm{k}=20$.

It must be noted that the results stemming from positive correlations between neuroimaging data and age would not be interpreted as "preserved regions", which would be a misuse of language: these analyses do not indicate if the GM volume or the metabolism remains stable, they only mean that these areas undergo the least impairment in comparison with the mean of GM/FDG uptake age-related decrease. Thus, the terms "less/least impairment/deterioration/ decrease" will be preferred to that of "preservation'.

\section{Results}


Tables 1 and 2 show the regions of significant links between GM volume (highest and lowest loss) and age. Results are illustrated in Figure 1A. Tables 3 and 4 show the regions of significant links between ${ }^{18}$ FDG uptake (highest and lowest decrease) and age. Results are illustrated in Figure 1B.

\subsection{Absolute GM volume loss (Table 1, Figure 1A)}

Absolute age-related GM volume loss was mainly located bilaterally in the frontal lobes (dorsolateral prefrontal cortex, sensorimotor areas and orbitofrontal regions). Atrophy was also found in the bilateral superior occipital and superior parietal cortices, the insular region surrounding the superior temporal areas, the posterior part of the hippocampus, the cerebellum and the periventricular areas spanning the caudate nuclei and anterior thalamic nucleus.

\subsection{Least GM volume decreases (Table 2, Figure 1A)}

The positive correlation between age and GM volume showed that the least GM decline was mainly located in the anterior right mesial temporal lobe structures (and the left counterpart at $\mathrm{p}<0.05$ FDR corrected), including the anterior part of the hippocampus, entorhinal cortex and amygdala, lateral thalamic nuclei, right calcarine region and brainstem.

\subsection{Highest ${ }^{18}$ FDG uptake decreases (Table 3, Figure 1B)}

A relative age-related decrease in ${ }^{18} \mathrm{FDG}$ uptake was found bilaterally in the superior medial frontal, motor, anterior and middle cingulate cortices, as well as in the bilateral parietal regions (with left-sided predominance), including the supramarginal, superior and inferior parietal cortices. The metabolic rate of the superior temporal pole encroaching on the insular and orbitofrontal cortices was particularly affected. 
The least ${ }^{18}$ FDG uptake decreases with aging was found in the bilateral mesial temporal lobes (hippocampus, amygdala and parahippocampal gyrus). The putamen, pallidum and lateral thalamic nuclei were metabolically less impaired, as well as the right posterior cingulate cortex and precuneus, both sides of the occipito-temporal cortex (calcarine, fusiform, lingual and inferior occipital cortices) and the cerebellum.

\section{Discussion}

Our findings regarding absolute GM loss showed that aging mostly affects the neocortical areas, notably the prefrontal cortex, in accordance with the literature (see Introduction), and also the parietal cortex. Corroborating previous studies which had used the same optimized VBM methodology [29,31], we found that the thalamus (lateral nuclei) and the anterior hippocampal region showed the least impairment in older subjects, contrasting with GM loss in the anterior thalamic nuclei and a more caudal portion of the hippocampal formation. This finding may explain some of the discrepancies found in previous studies using the ROI method, as the ROI is potentially located in different places, while with voxelbased analysis the exact location of significant results is not pre-specified. Also, using the former method, the hippocampal head was found to be more resilient to the normal aging process than the hippocampal tail $[24,64]$, whereas in contrast a substantial decrease in anterior hippocampal volume has been observed in Alzheimer's disease $[4,43,64]$. Thus, this result signals a major difference between healthy aging and Alzheimer's disease.

Overall, the data from many recent studies, including ours, can be combined now to provide quite a clear picture of the relationship of hippocampal volume to age in normal individuals. The hippocampal volume increases in children [82], until in the young adult, then remains relatively stable until the late 60 's when it begins to decline (see introduction), giving rise to a curvilinear function. As we have studied very young adults in their 20 's and only few 
individuals past age 70, a "linear" regression revealed no effect. Moreover, our findings highlighted different age effects in anterior and caudal hippocampal areas and it would be interesting to further study the hippocampal volume in all the lifespan, considering separately its different parts rather than the whole structure. Finally, it is worth noting that the gray matter losses in the frontal cortex and those in the hippocampus are very different, the decline in frontal cortex proceeding monotonically downward from an early age.

Regarding the metabolic data, we found that the anterior brain areas, notably a large part of the superior medial prefrontal cortex and the anterior and middle parts of the cingulate cortex, were the most metabolically affected in normal aging. Most previous studies have reported decreased activity in frontal areas and the anterior cingulate gyrus with age, using SPECT [44], $\left[{ }^{15} \mathrm{O}\right] \mathrm{H}_{2} \mathrm{O}$-PET [5,12,42,48,54] or ${ }^{18}$ FDG-PET [28,32,49,58,86,87,89]. We also found that the decrease in ${ }^{18}$ FDG uptake affected other neocortical regions, including the parietal and temporal poles, thereby corroborating a number of previous studies. Ibanez et al. [33] failed to find any remaining hypometabolic areas after PVEc. However, differences in the population and statistics they selected may have induced a loss of statistical power in their study, as they have compared two small groups (young vs. older groups), rather than correlating PET data and age across the whole sample.

Consistent with the literature, less metabolic decrease was found within the inferior temporal (fusiform cortex) and occipital areas (calcarine area and lingual gyrus) [32,49,58,86]. These cortical areas either form an extension, or are located very close to, the limbic and paralimbic areas, which were also less impaired. One of the limbic structures - the hippocampus - showed a lesser degree of metabolic impairment, thus confirming the findings of Willis et al. [86], who found 'preserved' hippocampal relative CMRglc (cerebral metabolic rate of glucose), and those of a very recent longitudinal study [5] over 9 years in older healthy subjects which highlighted an increased relative $\mathrm{rCBF}$ in the left hippocampus. In the past, suboptimal 
methodology may have obscured structures of small size located close to the ventricles, such as the hippocampal structures, basal ganglia and thalamus, as PVE reduces the spatial resolution of the data and causes the metabolic rate to be underestimated. For instance, the failure to find a positive correlation between age and hippocampal metabolism in most of the studies that failed to correct for PVE, except those cited above, may reflect the contamination of hippocampal voxel values by the CSF values of the surrounding ventricles, which enlarge with age.

It is worth noting that the posterior cingulate cortex is one of the least metabolically impaired areas with healthy aging. An increasing number of studies have consistently showed that this structure is the most metabolically impaired region in prodromal Alzheimer's disease $[15,53]$, once again revealing a major difference between this neurodegenerative disease and normal aging $[58,86]$. By controlling for errors liable to generate inaccurate findings, our data provide further evidence that the subcortical nuclei (putamen, pallidum) and thalamus are quite spared by increasing age. Previous studies have yielded discrepant results regarding these structures, reporting either 'preservation' [49,58,86], or alteration (before PVEc [33], see also [32]).

From an evolutionary perspective, our structural findings support the "developmental hypothesis" postulated by Grieve et al. [31] to account for structural changes in normal aging. This hypothesis stipulates that the first structures to neurally develop are the most resistant to aging effects, whereas those that emerge during the latter stages of development are the first to deteriorate. Phylogenetically, the neocortex and, more specifically, the prefrontal cortex, belong to the neencephalon, corresponding to the third and last level of development of the central nervous system, while the hippocampus belongs to the archeocortex, which corresponds to the first level of development. The thalamus belongs to the paleocortex, second level of development. Ontogenesis follows the phylogenetic axis: histological and 
MRI analyses [60,62] of normal foetal brain development have highlighted the early maturation of the hippocampus and thalamus (see also [82]).

Can this theory be applied to the metabolic findings measured by ${ }^{18}$ FDG uptake? According to ${ }^{18}$ FDG-PET studies of the postnatal maturation of the brain [16], the newborn period is characterized by a high metabolic rate in the mesial temporal region, cerebellar vermis, thalamus, basal ganglia, cingulate cortex and sensorimotor cortex. At three months, glucose metabolism increases in the parietal, occipital and temporal cortices. Frontal glucose consumption begins to increase later, between six and eight months. Thus, our results are broadly congruent with metabolic ontogenetic development.

Our findings reveal a clear opposition between the decline in frontal structures and the clearly lesser alteration of GM volume and FDG uptake of the hippocampal region. They make an interesting contribution to our understanding not only of age-related memory impairment but also of spared processes in older subjects. Thus, these areas are known to subtend episodic memory, although their roles can be dissociated [9]. Although both the encoding and retrieval processes of episodic memory depend on frontal cortex integrity, some authors have suggested that the frontal cortex may be involved more in effortful strategic processes associated with memory retrieval, while the hippocampus is mainly engaged in the encoding and ecphoric processes $[11,20,22,50,78]$. Thus, our findings support the idea that episodic memory deficits associated with normal aging reflect above all a failure to implement an efficient strategy in the retrieval of episodic information, with encoding and ecphoric processes being relatively unaffected. Several lines of evidence from PET and fMRI activation studies $[7,11,77,78,79]$ support this interpretation, demonstrating that frontal dysfunction during episodic memory tasks in older subjects reflects age-related changes in their retrieval strategies [77]. Activation studies have shown that, unlike young subjects where 
the frontal cortex is more heavily activated on the right than the left during retrieval (the HERA model, Hemispheric Encoding/Retrieval Asymmetry [83]), older adults show overactivation (a bilateral pattern of frontal activity) (see the HAROLD model, Hemispheric Asymmetry Reduction in OLDer adults, [10]) or under-activation. Structural and functional bilateral frontal shrinkage would induce compensatory mechanisms, explaining why older adults display more frontal activity during retrieval tasks [57]. The contrast here with Alzheimer's disease is worth noting, where episodic memory impairment is associated with hippocampal dysfunction shown by correlative [15,20,21,26] and activation [23,55,79] studies.

Our interpretation regarding the origin of memory decline in normal aging, especially concerning the medial temporal lobe, is in line with a recent longitudinal study [6] reporting functional age-related changes: the authors assessed memory over 9 years using PET in 25 healthy and cognitively stable older adults. While subjects' performance did not decrease over time, widespread changes in relative $\mathrm{rCBF}$ were observed during memory tasks over time, particularly increasing activity in the medial temporal structures. The authors suggested that these changes might sustain memory performance in older subjects. The patterns they observed fit with the notion of preserved hippocampal function with advancing age in healthy individuals. Furthermore, the dissociation between the preservation of the anterior part of the hippocampal region and the deterioration of its caudal portion fits well with the idea of the preferential age-related maintenance of encoding processes, as suggested in the HIPER (hippocampal encoding/retrieval) model [39]. According to this model, the rostral portion of the hippocampus is particularly heavily involved in encoding processes, whereas its caudal portion is mainly involved in retrieval processes.

Methodological considerations

PET 
All PET data were expressed as relative values, since we used raw FDG uptake data, which have to be divided by the global mean because they have no physiological meaning. Although it would have been of interest to use CMRglc values in this study, these data were not available to us, as they require invasive arterial blood sampling. However, our method allowed us to highlight both the most and the least altered structures, according to our goal. Another methodological issue regarding PET concerns the spatial normalization: some authors have suggested that voxel-based methods entail problems with spatial alignment of relatively small structures like the hippocampus, which is subject to high anatomic variability. Since the age-related hippocampal changes constitute an important issue, in order to ensure that our voxel-based SPM findings were not due to a spatial normalization problem, we have performed further complementary analyses, based on Mosconi et al. [51] and termed HipMask. This method considers only those hippocampal voxels common to a high majority of subjects, thus reducing errors due to spatial normalization and anatomical mismatch. Using this method, the results were in agreement with the SPM analysis: there was a positive correlation between relative metabolic hippocampal ratios and age $(\mathrm{r}=.51, \mathrm{p}<.001)$. Moreover, we found substantial correlations between the measures obtained in each subject using the HipMask method, and the intensity values extracted from the voxel-based analysis in the left $[-36 ;-14 ;-18]$ and right $[38 ;-22 ;-12]$ hippocampal peaks $(\mathrm{r}=.73$ and $\mathrm{r}=.70$, respectively, $\mathrm{p}<.001$ for both), suggesting that the SPM findings are robust and not due to spatial normalization errors.

\section{Structural MRI}

Using VBM to address regional volumetric changes could be open to criticisms notably for structures such as the hippocampus. However, we chose to use this approach (for both MR and PET data sets) not only to objectively study the whole brain, but also to show local changes. For instance, we found an absolute GM loss in the posterior part of the 
hippocampus, but a lesser GM loss in its anterior part. However, we also performed complementary ROI analysis centred on the head of the right hippocampus in the whole sample $(\mathrm{N}=45)$, in order to compare the SPM- and ROI-derived results. To this end, we have manually drawn each subject's head of the hippocampus. The anatomical boundaries used for hippocampus head segmentation were as follows: the principal orientation for segmentation was the coronal view, neither the amygdala nor the entorhinal cortex were included; ROI drawing was performed in the antero-posterior direction, the ROI including the subiculum and the uncus up to its head. The ROIs were expressed in $\mathrm{mm}^{3}$, and these raw volumes were normalized by the global mean, i.e., the mean intensity value of all the voxels, to be as consistent as possible regarding the comparison with VBM data which were also normalized by these values. The correlation between age and hippocampal head volume was $\mathrm{r}=.07(\mathrm{p}=$ .65 ), i.e. there is no hippocampal head volume decrease with normal aging (Figure 2) (see [24] for similar results). This result fits well with our interpretation of the voxel-based analysis. Of note, it is not surprising not to find a significant positive correlation, since the ROIs do not correspond exactly to the cluster generated by SPM, which included the uncus except its head, and part of the subiculum, entorhinal cortex and amygdala. Moreover, we have noted the wide variability of the anterior hippocampal volume across all age ranges, a point also highlighted in a very recent study [41]. The purpose of the authors was to determine whether there were differences in the variance of the whole hippocampal volume associated with age. They showed that the variance of hippocampal volume was not different in young and older adults, and they gave an interesting discussion about the large hippocampal volume inter-individual variability they observed in young healthy subjects.

\section{Limitations of the study}

This study has a few potential limitations. Firstly, due to the disparity between PET and MR spatial resolution, both data sets could not be directly compared. However, providing 
quantitative or statistical comparison between the degree of atrophy and hypometabolism was not the aim of the present study. Secondly, we note the remote possibility of age effects on intrinsic MR signal and contrast. Thirdly, we admit that the accuracy of PVC algorithms is highly dependent on the degree of accuracy achieved by the MRI-PET realignment and MRI segmentation procedures, as assessed in many previous studies (for reviews, see $[61,74,88]$ ). Although there is no given segmentation or PVE correction algorithms providing the best results under all conditions, the SPM segmentation algorithm seems to be more particularly recommended for clinical data [88], and the modified Müller-Gärtner PVE correction algorithm seems to be the most accurate voxel-based method, and the least dependent on segmentation errors [61]. Under these conditions, and considering the fact that coregistration and segmentation have been individually checked for accuracy, we can consider that we have done our best to reduce (although not totally exclude) the risk of realignment and segmentation errors. Finally, our cross-sectional study is not adequate to conclude definitively on the issue of the high or low level of impairment of the hippocampus, notably because such studies could be influenced by cohort effects. Although a longitudinal PET-MR combined study would obviously be of considerable interest, the advantage of this approach relative to cross-sectional designs has been occasionally [40,65], but not consistently [27,75], shown.

\section{Conclusion}

Overall, the neurobiological changes in normal aging highlighted in this study support the developmental theory whereby brain changes follow the phylogenetic and ontogenetic axes, and are consistent with age-related changes in memory performance. Our findings also highlight the differences between brain impairment associated with normal aging and those which characterize Alzheimer's disease. It is well-known that in prodromal Alzheimer's disease, the hippocampus is the first to become atrophic [14], while the posterior cingulate cortex undergoes early hypometabolism $[15,53]$. In our study of healthy subjects, we found 
the reverse pattern, i.e. the anterior hippocampal formation volume and the posterior cingulate glucose metabolism were the least altered, signaling the parting of the ways between normality and pathology.

Acknowledgements: The authors are grateful to Ms F Mézenge, Ms M-H Noël, Ms A Pélerin, Dr V de la Sayette, Mr Ph Conejero, Mr D Luet, Mr O Tirel, Mr V Beaudouin, Ms N Jacques for their help in this study, and the anonymous Referees for their helpful comments. This research was funded by the G.I.S. Institut de la longévité et du vieillissement, Inserm.

\section{References}

[1] Abe O, Yamasue H, Aoki S, Suga M, Yamada H, Kasai K, Masutani Y, Kato N, Kato N, Ohtomo K. Aging in the CNS: comparison of gray/white matter volume and diffusion tensor data. Neurobiol Aging 2006, Ahead of print.

[2] Allen JS, Bruss J, Brown CK, Damasio H. Normal neuroanatomical variation due to age: The major lobes and a parcellation of the temporal region. Neurobiol Aging 2005; 26: 1245-60.

[3] Baron JC, Godeau C. Human aging. In: Brain Mapping: The Systems (Mazziotta JC, Toga A, eds), pp. 591-604. San Diego: Academic Press, 2000. 
[4] Baron JC, Chételat G, Desgranges B, Perchey G, Landeau B, de la Sayette V, Eustache F. In vivo mapping of gray matter loss with voxel-based morphometry in mild Alzheimer's disease. Neuroimage 2001; 14: 298-309.

[5] Beason-Held LL, Kraut MA, Resnick SM. I. Longitudinal changes in aging brain function. Neurobiol Aging (2006), doi: 10.1016/j.neurobiolaging.2006.10.031

[6] Beason-Held LL, Kraut MA, Resnick SM. II. Temporal patterns of longitudinal change in aging brain function. Neurobiol Aging (2006), doi: 10.1016/j.neurobiolaging.2006.11.011

[7] Bernard F, Desgranges B, Eustache F, Baron J-C. Neural correlates of age-related verbal episodic memory decline: A PET study with combined subtraction/correlation analysis. Neurobiol Aging 2006; Ahead of print.

[8] Bigler ED, Blatter DD, Anderson CV, Johnson SC, Gale SD, Hopkins RO, Burnett B. Hippocampal volume in normal aging and traumatic brain injury. Am J Neuroradiol 1997; $18: 11-23$.

[9] Buckner RL. Memory and executive function in aging and AD: multiple factors that cause decline and reserve factors that compensate. Neuron 2004; 44: 195-208.

[10] Cabeza R. Hemispheric asymmetry reduction in older adults: the HAROLD model. Psychol Aging 2002; 17: 85-100.

[11] Cabeza R, Nyberg L. Imaging cognition II: an empirical review of 275 PET and fMRI studies. J Cogn Neurosci 2000; 12: 1-47.

[12] Calautti C, Serrati C, Baron JC. Effects of age on brain activation during auditorycued thumb-to-index opposition. Stroke 2001; 32: 139-46. 
[13] Cardebat D, Doyon B, Puel M, Goulet P, Joanette Y. Evocation lexicale formelle et sémantique chez des sujets normaux: performances et dynamiques de production en fonction du sexe, de l'âge et du niveau d'étude. Acta neurol Belg 1990 ; 90: 207-17.

[14] Chételat G, Desgranges B, de la Sayette V, Viader F, Eustache F, Baron JC. Mapping gray matter loss with voxel-based morphometry in mild cognitive impairment. Neuroreport 2002; 13: 1939-43.

[15] Chételat G, Desgranges B, de la Sayette V, Viader F, Berkouk K, Landeau B, Lalevée C, Le Doze F, Dupuy B, Hannequin D, Baron JC, Eustache F. Dissociating atrophy and hypometabolism impact on episodic memory in mild cognitive impairment. Brain 2003; 126:1955-67.

[16] Chugani HT. A critical period of brain development: studies of cerebral glucose utilization with PET. Prev Med 1998; 27: 184-8.

[17] Cohen RM, Szczepanik J, McManus M, Mirza N, Putnam K, Levy J, Sunderland T. Hippocampal atrophy in the healthy is initially linear and independant of age. Neurobiol Aging 2006; 27: 1385-94.

[18] Collignon A, Maes F, Delaere D, Vandermeulen D, Suetens P, Marchal G. Automated multi-modality image registration based on information theory. In Bizais, Barillot \& Di Paola, eds, Information Processing in Medical Imaging, pp 263-74, Dordrecht, The Netherlands. Kluwer Academic Publishers, 1995.

[19] Delacourte A, David JP, Sergeant N, Buée L, Wattez A, Vermersch P, Ghozali F, Fallet-Bianco C, Pasquier F, Lebert F, Petit H, Di Menza C. The biochemical pathway of neurofibrillary degeneration in aging and Alzheimer's disease. Neurology 1999; 52: 115665. 
[20] Desgranges B, Baron JC, Eustache F. The functional neuroanatomy of episodic memory: the role of the frontal lobes, the hippocampal formation, and other areas. Neuroimage 1998; 8: 198-213.

[21] Desgranges B, Baron JC, Lalevée C, Giffard B, Viader F, de la Sayette V, Eustache F. The neural substrates of episodic memory impairment in Alzheimer's disease as revealed by FDG-PET: relationship to degree of deterioration. Brain 2002a; 125: 1116-24.

[22] Desgranges B, Baron JC, Giffard B, Chételat G, Lalevée C, Viader F, de la Sayette $\mathrm{V}$, Eustache F. The neural basis of intrusions in free recall and cued recall: a PET study in Alzheimer's disease. Neuroimage 2002b; 17: 1658-64.

[23] Dickerson BC, Salat DH, Greve DN, Chua EF, Rand-Giovannetti E, Rentz DM, Bertram L, Mullin K, Tanzi RE, Blacker D, Albert MS, Sperling RA. Increased hippocampal activation in mild cognitive impairment compared to normal aging and AD. Neurology 2005; 65: 404-11.

[24] Driscoll I, Hamilton DA, Petropoulos H, Yeo RA, Brooks WM, Baumgartner RN, Sutherland RJ. The aging hippocampus: cognitive, biochemical and structural findings. Cereb Cortex 2003; 13:1344-51.

[25] Eustache F., Desgranges B., Lalevée C. L'évaluation clinique de la mémoire. Revue Neurologique (Paris) 1998; 154: 18-32.

[26] Eustache F, Desgranges B, Giffard B, de la Sayette V, Baron JC. Entorhinal cortex disruption causes memory deficit in early Alzheimer's disease as shown by PET. Neuroreport 2001; 12:683-5. 
[27] Fotenos AF, Snyder AZ, Girton LE, Morris JC, Buckner RL. Normative estimates of cross-sectional and longitudinal brain volume decline in aging and AD. Neurology 2005; 64: 1032-9.

[28] Garraux G, Salmon E, Degueldre C, Lemaire C, Laureys S, Franck G. Comparison of impaired subcortico-frontal metabolic networks in normal aging, subcortico-frontal dementia, and cortical frontal dementia. Neuroimage 1999; 10: 149-62.

[29] Good CD, Johnsrude IS, Ashburner J, Henson RNA, Friston KJ, Frackowiak RSJ. A voxel-based morphometric study of aging in 465 normal adult human brains. Neuroimage 2001; 14: 21-36.

[30] Grady CL. Functional brain imaging and age-related changes in cognition. Biol Psychology 2000; 54: 259-81.

[31] Grieve SM, Clark CR, Williams LM, Peduto AJ, Gordon E. Preservation of limbic and paralimbic structures in aging. Hum Brain Mapp 2005; 25: 391-401.

[32] Herholz $\mathrm{K}$ et al. Discrimination between Alzheimer dementia and controls by automated analysis of multicenter FDG PET. Neuroimage 2002; 17: 302-16.

[33] Ibanez V, Pietrini P, Furey ML, Alexander GE, Millet P, Bokde ALW, Teichberg D, Schapiro MB, Horwitz B, Rapoport SI. Resting state glucose metabolism is not reduced in normotensive healthy men during aging, after correction for brain atrophy. Brain Res Bull 2004; 63: 147-54.

[34] Jernigan TL, Archibald SL, Fennema-Notestine C, Gamst AC, Stout JC, Bonner J, Hesselink JR. Effects of age on tissues and regions of the cerebrum and cerebellum. Neurobiol Aging 2001; 22: 581-94. 
[35] Jernigan TL, Gamst AC. Changes in volume with age-consistency and interpretation of observed effects. Neurobiol Aging 2005; 26: 1271-4.

[36] Kantarci K, Jack CR Jr. Neuroimaging in Alzheimer disease: an evidence-based review. Neuroimaging Clin N Am 2003; 13: 197-209.

[37] Lehmbeck JT, Brassen S, Weber-Fahr W, Braus DF. Combining voxel-based morphometry and diffusion tensor imaging to detect age-related brain changes. Neuroreport 2006; 17: 467-70.

[38] Lemaître H, Crivello F, Grassiot B, Alpérovitch A, Tzourio C, Mazoyer B. Age- and sex-related effects on the neuroanatomy of healthy elderly. Neuroimage 2005 ; 26: 900-11.

[39] Lepage M, Habib R, Tulving E. Hippocampal PET activations of memory encoding and retrieval: the HIPER model. Hippocampus 1998; 8:313-22.

[40] Liu RSN, Lemieux L, Bell GS, Sisodiya SM, Shorvon SD, Sander JWAS, Duncan JS. A longitudinal study of brain morphometrics using quantitative magnetic resonance imaging and difference image analysis. Neuroimage 2003; 20: 22-33.

[41] Lupien SJ, Evans A, Lord C, Miles J, Pruessner M, Pike B, Pruessner JC. Hippocampal volume is as variable in young as in older adults: implications for the notion of hippocampal atrophy in humans. Neuroimage 2007; 34: 479-85.

[42] Martin AJ, Friston KJ, Colebatch JG, Frackowiak RSJ. Decreases in regional cerebral blood flow with normal aging. J Cereb Blood Flow Metab 1991; 11: 684-9.

[43] Matsuda H, Kitayama N, Ohnishi T, Asada T, Nakano S, Sakamoto S, Imabayashi E, Katoh A. Longitudinal evaluation of both morphologic and functional changes in the same individuals with Alzheimer's disease. J Nucl Med 2002; 43: 304-11. 
[44] Matsuda H, Ohnishi T, Asada T, Li Z, Kanetaka H, Imabayashi E, Tanaka F, Nakano

S. Correction for partial-volume effects on brain perfusion SPECT in healthy men. J Nucl Med 2003; 44: 1243-52.

[45] Mattis S. Mental status examination for organic mental syndrome in the elderly patient. In: Mental Status Examination for Organic Mental Syndrome in the Elderly Patients (Bellack L, Karasu TB, eds),. pp. 77-101. New York: Grune \& Stratton, 1976.

[46] Meguro K, Constans JM, Courtheoux P, Theron J, Viader F, Yamadori A. Atrophy of the corpus callosum correlates with white matter lesions in patients with cerebral ischaemia. Neuroradiology 2000; 42: 416-9.

[47] Meltzer CC, Becker JT, Price JC, Moses-Kolko E. Positron emission tomography imaging of the aging brain. Neuroimag Clin N Am 2003; 13: 759-67.

[48] Meltzer CC, Cantwell MN, Greer PJ, Ben-Eliezer D, Smith G, Frank G, Kaye WH, Houck PR, Price JC. Does cerebral blood flow decline in healthy aging? A PET study with partial-volume correction. J Nucl Med 2000; 41: 1842-8.

[49] Moeller JR, Ishikawa T, Dhawan V, Spetsieris P, Mandel F, Alexander GE, Grady C Pietrini P, Eidelberg D. The metabolic topography of normal aging. J Cereb Blood Flow Metab 1996; 16: 385-98.

[50] Morcom A, Good C, Frackowiak R, Rugg M. Age effects on the neural correlates of successful memory encoding. Brain 2003; 126: 213-29.

[51] Mosconi L, Tsui WH, De Santi S, Li J, Rusinek H, Convit A, Li Y, Boppana M, de Leon MJ. Reduced hippocampal metabolism in MCI and AD : automated FDG-PET image analysis. Neurology 2005; 64: 1860-7. 
[52] Müller-Gärtner HW, Links JM, Prince JL, Bryan RN, McVeigh E, Leal JP, Davatzikos C, Frost JJ. Measurement of radiotracer concentration in brain gray matter using positron emission tomography: MRI-based correction for partial volume effects. J Cereb Blood Flow Metab 1992; 12: 571-83.

[53] Nestor PJ, Fryer TD, Ikeda M, Hodges JR. Retrosplenial cortex (BA29/30) hypometabolism in mild cognitive impairment (prodromal Alzheimer's disease). Eur J Neurosci 2003; 18: 1-5.

[54] Pantano P, Baron JC, Lebrun-Grandie P, Duquesnoy N, Bousser MG, Comar D. Regional cerebral blood flow and oxygen consumption in human aging. Stroke $1984 ; 15$ : $635-41$

[55] Pariente J, Cole S, Henson R, Clare L, Kennedy A, Rossor M, Cipoloti L, Puel M, Demonet JF, Chollet F, Frackowiak RSJ. Alzheimer's patients engage an alternative network during a memory task. Ann Neurol 2005; 58: 870-9.

[56] Park DC, Gutchess AH. Aging, cognition, and culture: a neuroscientific perspective. Neurosci Biobehav Rev 2002; 26: 859-67.

[57] Persson J, Nyberg L. Altered brain activity in healthy seniors: what does it mean? Prog Brain Res 2006; 157 :45-56.

[58] Petit-Taboué MC, Landeau B, Desson JF, Desgranges B, Baron JC. Effects of healthy aging on the regional cerebral metabolic rate of glucose assessed with statistical parametric mapping. Neuroimage 1998; 7: 176-84.

[59] Pfefferbaum A, Sullivan EV, Rosenbloom MJ, Mathalon DH, Lim KO. A controlled study of cortical gray matter and ventricular changes in alcoholic men over a 5-year interval. Arch Gen Psychiatry 1998; 55: 905-12. 
[60] Prayer D, Kasprian G, Krampl E, Ulm B, Witzani L, Prayer L, Brugger PC. MRI of normal fetal brain development. Eur J Radiol 2006; 57:199-216.

[61] Quarantelli M, Berkouk K, Prinster A, Landeau B, Svarer C, Balkay L, Alfano B, Brunetti A, Baron JC. Integrated software for the analysis of brain PET/SPECT studies with partial-volume-effect correction. J Nucl Med 2004; 45: 192-201.

[62] Rados M, Judas M, Kostovic I. In vitro MRI of brain development. Eur J Radiol 2006; 57:187-98.

[63] Raz N. Ageing and the brain. In: Encyclopedia of Life Sciences. London: Nature Publishing Group, 2001.

[64] Raz N. Aging of the brain and its impact on cognitive performance: integration of structural and functional findings. In: Handbook of aging and cognition-II (Craik FIM, Salthouse TA, eds), pp.1-90. Mahwah, NJ: Erlbaum, 2000.

[65] Raz N, Lindenberger U, Rodrigue KM, Kennedy KM, Head D, Williamson A, Dahle C, Gerstorf D, Acker JD. Regional brain changes in aging healthy adults: General trends, individual differences and modifiers. Cereb Cortex 2005; 15: 1676-89.

[66] Raz N, Gunning-Dixon F, Head D, Rodrigue KM, Williamson A, Acker JD. Aging, sexual dimorphism, and hemispheric asymmetry of the cerebral cortex: replicability of regional differences in volume. Neurobiol Aging 2004; 25: 377-96.

[67] Raz N, Rodrigue KM, Head D, Kennedy KM, Acker JD. Differential aging of the medial temporal lobe: a study of a five-year change. Neurology 2004; 62: 433-8.

[68] Raz N, Gunning FM, Head D, Dupuis JH, McQuain J, Briggs SD, Loken WJ, Thornton AE, Acker JD. Selective aging of the human cerebral cortex observed in vivo: Differential vulnerability of the prefrontal gray matter. Cereb Cortex 1997; 7: 268-82. 
[69] Resnick SM, Pham DL, Kraut MA, Zonderman AB, Davatzikos C. Longitudinal magnetic resonance imaging studies of older adults: A shrinking brain. J Neurosci 2003; 23: 3295-01.

[70] Resnick SM, Goldszal AF, Davatzikos C, Golski S, Kraut MA, Metter EJ, Bryan RN, Zonderman AB. One-year age changes in MRI brain volumes in older adults. Cereb Cortex 2000; 10: 464-72.

[71] Rettmann ME, Kraut MA, Prince JL, Resnick, SM. Cross-sectional and longitudinal analyses of anatomical sulcal changes associated with aging. Cereb Cortex 2006; 16: 1584-94.

[72] Rousset OG, Ma Y, Evans AC. Correction for partial volume effects in PET: principle and validation. J Nucl Med 1998; 39: 904-11.

[73] Rousset OG, Ma Y, Wong DF, Evans AC. Pixel- versus region-based partial volume correction in PET. In: Quantitative Functional Brain Imaging with Positron Emission Tomography (Carson RE, Herscovitch P, Daube-Witherspoon M, eds), pp. 67-75. San Diego, CA: Academic Press, 1998.

[74] Rousset O, Zaidi H. Correction for partial volume effects in emission tomography. In: Quantitative Analysis in Nuclear Medicine Imaging (Zaidi H, Ed), pp. 236-71. New York: Springer, 2005.

[75] Salat DH, Buckner RL, Snyder AZ, Greve DN, Desikan RSR, Busa E, Morris JC, Dale AM, Fischl B. Thinning of the cerebral cortex in aging. Cereb Cortex 2004; 14: 72130. 
[76] Scahill RI, Frost C, Jenkins R, Whitwell JL, Rossor MN, Fox NC. A longitudinal study of brain volume changes in normal aging using serial registered magnetic resonance imaging. Arch Neurol 2003; 60: 989-94.

[77] Schacter DL, Wagner AD. Medial temporal lobe activations in fMRI and PET studies of episodic encoding and retrieval. Hippocampus 1999; 9: 7-24.

[78] Schacter DL, Savage CR, Alpert NM, Rauch SL, Albert MS. The role of hippocampus and frontal cortex in age-related memory changes: a PET study. Neuroreport 1996; 7: 1165-9.

[79] Sperling RA, Bates JF, Chua EF, Cocchiarella AJ, Rentz DM, Rosen BR, Schacter DL, Albert MS. fMRI studies of associative encoding in young and elderly controls and mild Alzheimer's disease. J Neurol Neurosurg Psych 2003; 74: 44-50.

[80] Sullivan EV, Marsh L, Pfefferbaum A. Preservation of hippocampal volume throughout adulthood in healthy men and women. Neurobiol Aging 2005; 26: 1093-8.

[81] Tisserand DJ, van Boxtel MPJ, Pruessner JC, Hofman P, Evans AC, Jolles J. A voxel-based morphometric study to determine individual differences in gray matter density associated with age and cognitive change over time. Cereb Cortex 2004; 14:96673.

[82] Toga AW, Thompson PM, Sowell ER. Mapping brain maturation. Trends Neurosci 2006; 29: 148-59.

[83] Tulving E, Kapur S, Craik FIM, Moscovitch M, Houle S. Hemispheric encoding retrieval asymmetry in episodic memory: positron emission tomography findings. Proc Natl Acad Sci U S A 1994; 91:2016-20. 
[84] Van Laere KJ, Dierckx RA. Brain perfusion SPECT: age- and sex-related effects correlated with voxel-based morphometric findings in healthy adults. Radiology 2001; 221: $810-7$.

[85] Walhovd KB, Fjell AM, Reinvang I, Lundervold A, Dale AM, Eilertsen DE, Quinn BT, Salat D, Makris N, Fischl B. Effects of age on volumes of cortex, white matter and subcortical structures. Neurobiol Aging 2005; 26: 1261-70.

[86] Willis MW, Ketter TA, Kimbrell TA, George MS, Herscovitch P, Danielson AL, Benson BE, Post RM. Age, sex and laterality effects on cerebral glucose metabolism in healthy adults. Psychiatry Res (Neuroimaging) 2002; 114: 23-37.

[87] Yanase D, Matsunari I, Yajima K, Chen W, Fujikawa A, Nishimura S, Matsuda H, Yamada M. Brain FDG PET study of normal aging in Japanese: effect of atrophy correction. Eur J Nucl Med Mol Imaging 2005; 32: 794-805.

[88] Zaidi H, Ruest T, Schoenahl F, Montandon ML. Links comparative assessment of statistical brain MR image segmentation algorithms and their impact on partial volume correction in PET. Neuroimage 2006; 32: 1591-607.

[89] Zuendorf G, Kerrouche N, Herholz K, Baron JC. Efficient principal component analysis for multivariate 3D voxel-based mapping of brain functional imaging data sets as applied to FDG-PET and normal aging. HumBrain Mapp 2003; 18: 13-21. 


\section{Legends}

Fig.1. Structural (A) and ${ }^{18}$ FDG uptake (B) changes occurring in normal aging. (A1) Threedimensional rendering (top), sagittal view (bottom) and scatterplots of adjusted activity value of the absolute GM loss in the frontal cortex (peak coordinates $[\mathrm{x} ; \mathrm{y} ; \mathrm{z}] \leftrightarrow[49 ; 13 ; 47] ; \mathrm{r}=-$ $.64)$ and body of the hippocampus $([\mathrm{x} ; \mathrm{y} ; \mathrm{z}] \leftrightarrow[17 ;-30 ;-13] ; \mathrm{r}=-.51)$ as a function of age. (A2) Three-dimensional rendering (top), sagittal view (bottom) and the scatterplot of relative adjusted activity value in the right anterior hippocampal area as a function of age ([; y; $\mathrm{z}] \leftrightarrow$ $[21 ;-9 ;-29] ; \mathrm{r}=.65)^{*}$. (B1) Three-dimensional rendering showing highest ${ }^{18} \mathrm{FDG}$ uptake decrease and the scatterplot of relative adjusted activity value in the frontal cortex as a function of age $([\mathrm{x} ; \mathrm{y} ; \mathrm{z}] \leftrightarrow[8 ; 54 ; 36] ; \mathrm{r}=-.66)$. (B2) Three-dimensional rendering (centre) showing regions of lowest ${ }^{18} \mathrm{FDG}$ uptake decrease as a function of age, principally in the right posterior cingulate cortex (sagittal view, right) $([\mathrm{x} ; \mathrm{y} ; \mathrm{z}] \leftrightarrow[14 ;-48 ; 32] ; \mathrm{r}=.68)$ and mesial temporal regions (coronal view, left) $([\mathrm{x} ; \mathrm{y} ; \mathrm{z}] \leftrightarrow[38 ;-22 ;-12] ; \mathrm{r}=.64)^{*}$. Results are displayed at $\mathrm{p}<.01$ FDR corrected for multiple comparisons at the voxel level (extent of threshold at least 20 contiguous voxels), and superimposed onto the specific prior created from the VBM analysis described in section 2.2.

*These positive correlations do not reflect a genuine increase in GM volume or ${ }^{18}$ FDG uptake with age. Because the absolute values have been divided by the global mean in these analyses, the decrease of the global mean induced an increase of the relative values with age, indicating that the highlighted regions were those that undergo the least age-related GM loss and decreased ${ }^{18}$ FDG uptake.

Fig. 2. Scatterplot of the association between age and hippocampal's head volumes (in $\mathrm{mm}^{3}$ ) assessed with ROI methodology. 
Tab.1. Principal clusters of absolute GM volume loss as a function of age, with their main peaks. The labelling has been adjusted to the specific template created with the VBM processing ( $\mathrm{p}<.01$ FDR corrected threshold for multiple comparisons). Note: $\mathrm{k}=$ cluster size (in voxels). BA: Brodmann Area. L: left, R: right. ant = anterior ; inf = inferior; med = medial $;$ mid $=$ middle $;$ operc $=$ operculum $;$ post $=$ posterior $;$ SMA $=$ supplementary motor area sup $=$ superior. $\mathrm{L}=$ left $; \mathrm{R}=$ right.

Tab.2. Principal clusters of lowest GM volume loss as a function of age, with their main peaks. (see legend Table 1)

Tab.3. Principal clusters of highest ${ }^{18}$ FDG uptake decrease as a function of age, with their main peaks. (see legend Table 1)

Tab.4. Principal clusters of lowest ${ }^{18}$ FDG uptake decrease as a function of age, with their main peaks. (see legend Table 1) 
Table 1 Absolute GM volume loss as a function of age

\begin{tabular}{|c|c|c|c|c|c|c|}
\hline & & & & ABLE 1: & Absolute GM volume loss as a function of ag & \\
\hline & $\begin{array}{l}\mathrm{MNI} \\
\text { rdina }\end{array}$ & & $t_{\text {value }}$ & $\mathrm{k}$ & labeling & BA \\
\hline$x$ & $\mathrm{y}$ & $z$ & & & & \\
\hline 49 & 13 & 47 & 5.44 & 35973 & Orbitofrontal mid R & $11 / 47$ \\
\hline & & & & & Frontal inf/mid/sup R & $6 / 8 / 9 / 10 / 44 / 45 / 46$ \\
\hline & & & & & Pre/post-central R & $3 / 4 / 43$ \\
\hline 43 & -10 & 20 & 4.69 & 6231 & Insula/Heschl/Rolandic operc/ Temporal sup R & $48 / 22$ \\
\hline-26 & 4 & 65 & 5.14 & 36619 & orbitofrontal inf $/ \mathrm{mid} / \mathrm{sup} \mathrm{L}$ & $11 / 46 / 47$ \\
\hline & & & & & Frontal inf/mid/sup L & 8/9/44/45/46 \\
\hline & & & & & Precentral L & 6 \\
\hline & & & & & Insula/Rolandic operc/Heschl L & 48 \\
\hline 5 & 48 & 49 & 5.06 & 2889 & Frontal sup med R & $9 / 32$ \\
\hline & & & & & SMA R & 8 \\
\hline & & & & & Cingulate ant $/ \mathrm{mid} \mathrm{R}$ & 32 \\
\hline-3 & 46 & 49 & 4.07 & 2722 & Frontal sup med L & 9 \\
\hline & & & & & SMA L & $6 / 8$ \\
\hline 3 & 46 & -29 & 3.55 & 144 & Rectus R & 11 \\
\hline-2 & 48 & -28 & 3.34 & 46 & Rectus L & 11 \\
\hline-29 & -85 & 40 & 6.20 & 11544 & Occipital mid/sup L & $18 / 19$ \\
\hline & & & & & Parietal inf/sup L & 7 \\
\hline 31 & -79 & 43 & 5.24 & 10698 & Occipital mid/sup/Cuneus R & 19 \\
\hline & & & & & Parietal sup/Angular R & 7 \\
\hline-62 & -22 & 40 & 4.26 & 895 & Postcentral/Supramarginal L & $1 / 2 / 3 / 4$ \\
\hline-7 & -35 & 50 & 3.93 & 1481 & Cingulate mid $\mathrm{L}$ & 23 \\
\hline-1 & 2 & 5 & 5.67 & 7918 & Periventricular areas & \\
\hline & & & & & Caudate (tail) L/R & \\
\hline & & & & & Thalamus (anterior nuclei) $R$ & \\
\hline-43 & -51 & 16 & 4.08 & 216 & Temporal mid L & 21 \\
\hline 17 & -30 & -13 & 3.89 & 307 & $\begin{array}{l}\text { Lingual, parahippocampal, hippocampus } \\
\text { (post) } R\end{array}$ & $27 / 30$ \\
\hline 54 & -23 & -12 & 3.54 & 700 & Temporal mid/sup R & $21 / 22$ \\
\hline-46 & -46 & -41 & 5.13 & 31567 & Cerebellum L & \\
\hline & & & & & Parahippocampal L & $27 / 30$ \\
\hline 36 & -43 & -44 & 5.02 & 20725 & Cerebellum R & \\
\hline & & & & & Temporal inf/fusiform $\mathrm{R}$ & 20/37 \\
\hline
\end{tabular}


Table 2 Lowest GM volume loss as a function of age

\begin{tabular}{|c|c|c|c|c|c|c|}
\hline \multicolumn{7}{|c|}{ TABLE 2: Lowest GM volume loss as a function of age } \\
\hline \multicolumn{3}{|c|}{ MNI coordinates } & \multirow[t]{2}{*}{$t_{\text {value }}$} & \multirow[t]{2}{*}{$\mathrm{k}$} & \multirow[t]{2}{*}{ labeling } & \multirow[t]{2}{*}{$\mathrm{BA}$} \\
\hline $\mathrm{x}$ & $\mathrm{y}$ & $\mathrm{z}$ & & & & \\
\hline \multirow[t]{3}{*}{21} & -9 & -29 & 5.68 & 1902 & Entorhinal $\mathrm{R}$ & $28 / 36$ \\
\hline & & & & & Hippocampus (ant) R & \\
\hline & & & & & Amygdala $\mathrm{R}$ & \\
\hline-16 & -19 & 5 & 5.70 & 626 & Thalamus (lateral nuclei) L & \\
\hline 19 & -21 & 5 & 5.63 & 768 & Thalamus (lateral nuclei) $R$ & \\
\hline 8 & -99 & 4 & 4.76 & 46 & Calcarine R & 17 \\
\hline 0 & -27 & -12 & 5.83 & 828 & Brainstem & \\
\hline
\end{tabular}

Table 3 Highest ${ }^{18}$ FDG uptake decrease as a function of age

\begin{tabular}{|c|c|c|c|c|c|c|}
\hline \multicolumn{7}{|c|}{ TABLE 3: Highest ${ }^{18}$ FDG uptake decrease as a function of age } \\
\hline \multicolumn{3}{|c|}{$\begin{array}{c}\text { MNI } \\
\text { coordinates }\end{array}$} & \multirow[t]{2}{*}{$t_{\text {value }}$} & \multirow[t]{2}{*}{ k } & \multirow[t]{2}{*}{ labeling } & \multirow[t]{2}{*}{$\mathrm{BA}$} \\
\hline $\mathrm{x}$ & $\mathrm{y}$ & $z$ & & & & \\
\hline \multirow[t]{3}{*}{-4} & 20 & 66 & 6.46 & 2681 & Frontal mid/sup/sup med L & $9 / 10$ \\
\hline & & & & & Precentral/SMA L & $6 / 8$ \\
\hline & & & & & Cingulate ant/mid & 32 \\
\hline \multirow[t]{3}{*}{6} & 20 & 66 & 6.05 & 1520 & Frontal mid/sup/sup med R & $8 / 9 / 10$ \\
\hline & & & & & SMA R & 6 \\
\hline & & & & & Cingulate mid/ant $R$ & 32 \\
\hline \multirow[t]{2}{*}{54} & 20 & 34 & 5.95 & 463 & Precentral R & 6 \\
\hline & & & & & Frontal inf/mid R & $44 / 9$ \\
\hline \multirow[t]{2}{*}{-40} & 14 & -10 & 5.46 & 481 & Orbitofrontal inf $\mathrm{L}$ & $45 / 47$ \\
\hline & & & & & Insula L & 48 \\
\hline-2 & 14 & -22 & 4.97 & 84 & Rectus L & 11 \\
\hline 2 & 16 & -22 & 4.87 & 64 & Rectus R & 11 \\
\hline \multirow[t]{2}{*}{46} & 22 & -6 & 4.73 & 206 & Orbitofrontal inf $\mathrm{R}$ & $45 / 47$ \\
\hline & & & & & Insula R & 48 \\
\hline \multirow[t]{2}{*}{-36} & -52 & 56 & 7.54 & 1372 & Parietal inf/sup/supramarginal L & $7 / 40$ \\
\hline & & & & & Occipital mid/sup/Angular L & $19 / 39$ \\
\hline 58 & -26 & 50 & 5.01 & 740 & Supramarginal/parietal inf $R$ & $2 / 3 / 40$ \\
\hline 30 & -82 & 38 & 4.39 & 209 & Occipital mid/sup R & $7 / 19$ \\
\hline-46 & 16 & -16 & 4.98 & 162 & Temporal pole sup L & 38 \\
\hline 48 & 12 & -14 & 4.42 & 99 & Temporal pole sup $\mathrm{R}$ & 38 \\
\hline 58 & -66 & 22 & 4.05 & 82 & Temporal mid/sup/angular R & $22 / 39$ \\
\hline-62 & -32 & 18 & 3.70 & 24 & Temporal sup L & 42 \\
\hline
\end{tabular}


Table 4 Lowest ${ }^{18}$ FDG uptake decrease as a function of age

\begin{tabular}{|c|c|c|c|c|c|c|}
\hline \multicolumn{7}{|c|}{ TABLE 4: Lowest ${ }^{18}$ FDG uptake decrease as a function of age } \\
\hline \multicolumn{3}{|c|}{$\begin{array}{c}\mathrm{MNI} \\
\text { coordinates }\end{array}$} & \multirow[t]{2}{*}{$t_{\text {value }}$} & \multirow[t]{2}{*}{ k } & \multirow[t]{2}{*}{ labeling } & \multirow[t]{2}{*}{ BA } \\
\hline$x$ & $\mathrm{y}$ & z & & & & \\
\hline \multirow[t]{11}{*}{26} & -64 & 18 & 7.60 & 6071 & Amygdala $\mathrm{R}$ & \\
\hline & & & & & Hippocampus R & \\
\hline & & & & & Parahippocampal $\mathrm{R}$ & 36 \\
\hline & & & & & Cingulate post $R$ & 30 \\
\hline & & & & & Fusiform R & 37 \\
\hline & & & & & Calcarine/occipital inf/lingual $\mathrm{R}$ & $17 / 18 / 19$ \\
\hline & & & & & Cuneus R & 17 \\
\hline & & & & & Precuneus R & 7 \\
\hline & & & & & Temporal inf/mid/sup R & $21 / 22$ \\
\hline & & & & & Pallidum - Putamen R & \\
\hline & & & & & Insula/Rolandic operc R & 48 \\
\hline \multirow[t]{8}{*}{-36} & -16 & 22 & 6.68 & 3747 & Amygdala L & \\
\hline & & & & & Hippocampus L & \\
\hline & & & & & Parahippocampal L & 36 \\
\hline & & & & & Fusiform L & 37 \\
\hline & & & & & Calcarine/occipital inf/lingual L & $17 / 18 / 19$ \\
\hline & & & & & Temporal inf/mid L & $21 / 22$ \\
\hline & & & & & Pallidum - Putamen L & \\
\hline & & & & & Insula/Rolandic operc L & 48 \\
\hline-16 & -16 & 8 & 5.83 & 145 & Thalamus (lateral nuclei) L & \\
\hline 18 & -14 & 10 & 5.40 & 95 & Thalamus (lateral nuclei) R & \\
\hline 44 & -10 & 30 & 5.53 & 177 & Pre/Post-central R & $3 / 4$ \\
\hline-44 & -14 & 30 & 4.77 & 217 & Postcentral L & $3 / 4$ \\
\hline-30 & -46 & 38 & 4.91 & 42 & Parietal inf/Angular L & 40 \\
\hline-16 & -36 & 38 & 4.69 & 64 & Cingulate mid $\mathrm{L}$ & 23 \\
\hline 16 & -20 & 42 & 4.18 & 26 & Cingulate mid $\mathrm{R}$ & 23 \\
\hline-10 & -60 & -36 & 5.34 & 412 & Cerebellum L/R & \\
\hline
\end{tabular}

